\title{
A visão de escolares sobre drogas no uso de um jogo educativo
}

Sandra Rebello ${ }^{1}$

Simone Monteiro ${ }^{2}$

Eliane P. Vargas ${ }^{3}$

REBELLO, S.; MONTEIRO, S.; VARGAS, E. Student views on drugs in the use of an educational game. Interface Comunic, Saúde, Educ, v.5, n.8, p.75-88, 2001.

This essay emphasizes the relevance of cultural intervention in the use of educational technologies. To this end, it describes the perception of 62 students from government schools in Rio de Janeiro, concerning topics broached in the "Jogo da Onda" - a game on drug use - as well as the group's interest in the material. On the basis of focus groups, observation of games being played, and questionnaires, drug use has been shown to be related to peer pressure, easy access to drugs and the fact that individual or merely occasional consumption are not seen as behaviors capable of leading to chemical dependence. The dissonance between the students' view and the repressivepreventive and/or informational-technical discourse suggests that educational actions should focus on how the information transmitted is understood, with a view to developing interaction, dialogue, information and reflection.

KEYWORDS: Healthcare education; educational material; social representation; educational game.

Este estudo enfatiza a relevância da mediação cultural no uso de tecnologias educacionais. Para tal, descreve a percepção de 62 escolares da rede pública do Rio de Janeiro sobre temas abordados no Jogo da Onda, um jogo sobre o uso de drogas, e o interesse do grupo pelo material. A partir de grupos focais, observação das partidas $e$ questionários, foi observado que a iniciação ao uso de drogas está relacionada à: pressão social de grupo, fácil acesso às drogas e ao não reconhecimento de que o consumo pessoal, mesmo descontínuo, pode levar à dependência química. Dissonâncias entre a visão dos escolares e o discurso preventivo repressivo e/ou técnico informativo sugere que as ações educativas devem privilegiar formas de apreensão das informações transmitidas, focando a interatividade, a interlocução, a informação e a reflexão.

PALAVRAS-CHAVE: Educação em saúde; material pedagógico; representação social; jogo educativo.

\footnotetext{
1, 2 Pesquisadoras do Laboratório de Educação em Ambiente e Saúde, Depto de Biologia, Instituto Oswaldo Cruz / Fundação Oswaldo Cruz.

${ }^{3}$ Pesquisadora do Laboratório de Educação em Ambiente e Saúde, Departamento de Biologia, Instituto Oswaldo Cruz / Fundação Oswaldo Cruz e Centro de Saúde Escola GSE, Escola Nacional de Saúde Pública / Fundação Oswaldo Cruz. <piafi@fiocruz.br><smonteiro@ax.apc.org>
} 
Introdução

Este artigo focaliza a importância de se conhecer a percepção do usuário sobre as mensagens veiculadas em recursos de educação em saúde, face ao reconhecimento das diferenças sócio-econômicas e culturais entre os grupos populacionais que integram as sociedades modernas. Para tanto, apresenta a visão de jovens escolares da rede pública do Rio de Janeiro sobre temas relacionados ao consumo indevido de drogas ${ }^{4}$, abordados no Jogo da Onda (Edições Consultor, 1998) ${ }^{5}$. Afim de apontar indicadores da aceitação $e$ motivação do uso deste recurso em contexto educativo também será mencionada, de forma breve, a opinião dos/as escolares e de um grupo de educadoras sobre o Jogo da Onda. Cabe informar que os elementos que compõem o processo de interação desse jogo não foram aprofundados no presente texto, mas encontram-se contemplados no trabalho de Cortes (1999).

O referido jogo foi produzido pelo Laboratório de Educação em Ambiente e Saúde (LEAS) da Fundação Oswaldo Cruz. O LEAS desenvolve pesquisas voltadas para a produção, avaliação ${ }^{6}$ e divulgação de tecnologias educacionais em saúde, informadas por uma perspectiva pedagógica construtiva e participativa (Monteiro et al., 1994; Schall et al., 1999). Identificada com a relativização do enfoque epidemiológico de risco (Castiel, 1994), esta linha de investigação visa propor alternativas ao modelo biomédico hegemônico, centrado na transmissão de informações, ressaltando as singularidades materiais e simbólicas dos variados segmentos sociais.

\section{Fundamentos}

Para fundamentar a análise da percepção dos jovens acerca dos temas abordados no Jogo da Onda, optou-se por tecer considerações sobre: (1) a importância da mediação cultural e da subjetividade como elementos modeladores da visão dos usuários na utilização de tecnologias educacionais; (2) os limites e alcances dos programas de prevenção ao abuso de drogas.

O primeiro ponto apoia-se numa opção teórico-metodológica na qual o usuário é concebido como sujeito ativo no processo educativo/comunicativo (Vargas \& Siqueira, 1999). Nesta perspectiva, as investigações - a exemplo das atuais tendências da pesquisa em comunicação social, em particular a produção latino-americana ${ }^{7}$ - relativizam a subordinação do usuário ao texto a partir de duas variáveis: o entendimento da recepção como processo mediado e o receptor concebido como sujeito da engrenagem no processo comunicativo. Isto significa dizer que nos estudos de recepção de mensagens o receptor é um leitor com capacidade interpretativa sobre as mensagens que lhe são ofertadas. Esta relação, de natureza simbólica, encontra-se delimitada pelo estoque cultural e pela posição que cada usuário ocupa no cenário social, conformadora, em parte, de sua subjetividade.

Quanto ao segundo ponto assinalado, análises sobre programas preventivos ao uso indevido de drogas, apoiadas na contextualização histórica do fenômeno, apontam para o fracasso das políticas de prevenção
${ }^{4}$ Para a Organização Mundial da Saúde "droga é qualquer substância, administrada por qualquer via, que provoca alterações no comportamento ou na percepção da realidade". Tendo em vista as diversas atribuições, efeitos e classificações em torno do conceito de droga

(Cf. Escohotado, 1997), cabe destacar que neste trabalho tal termo está referido a qualquer substância psicoativa, lícita ou ilícita.

${ }^{5}$ Desenvolvido por Sandra Rebello e Simone Monteiro (pesquisadoras do LEAS, Biologia/IOC, FIOCRUZ), este jogo contém 1 tabuleiro; 1 dado; 4 pinos, 1 encarte com dicas de atividades e sugestões bibliográficas e quatro baralhos: o baralho laranja descreve $o$ conceito e efeitos de drogas lícitas e ilícitas; o baralho vermelho contém perguntas $e$ respostas sobre aspectos jurídicos, conceito e classificação das drogas e as conseqǜencias do uso abusivo; nos baralhos verde e o azul são apresentadas situações do cotidiano associadas ao consumo de drogas, como relacionamento

familiar, políticas educativas, conflitos pessoais; pressão social do grupo, dentre outros; o baralho verde difere do baralho azul por conter mensagens das autoras sobre o tema abordado na carta. O jogo foi projetado para ser jogado em dupla. Recomendado para maiores de 12 anos, é adequado para contextos do ensino formal e informal, podendo ser adaptado para diferentes realidades, inclusive programas dirigidos para dependentes químicos, conforme indica o encarte que acompanha o material. 
${ }^{6}$ Destaca-se a reduzida problematização dos usos e efeitos dos materiais educativos, no âmbito nacional, ainda que se possa reconhecer algumas iniciativas que contribuem para a acumulação de conhecimento nesse campo. Além das iniciativas dos LEAS, cabe mencionar outros esforços como o projeto PRISMA (Barros et al, 1999) e as produções do Núcleo de Tecnologia Educacional para a Saúde/UFRJ (Sá et al 1999).

${ }^{7}$ Sobre a trajetória latino-americana da pesquisa em comunicação ver Melo (1985) e Neto (1995) sobre pesquisas de recepção. centradas apenas na repressão (Bucher, 1992; Inem \& Acselrad, 1993; Bastos, 1995). Segundo Vargas (1998), pode-se encontrar no cenário social a sobreposição de uma racionalidade dominante técnico-científica, presente nos modelos de atenção à saúde, a outras racionalidades onde a droga é vista como um mal em si. Tal fato contribui para a descontextualização das diferentes modalidades de usos e de usuários. Parece prevalecer a condenação moral sobre o consumo de determinadas substâncias. Assim, cabe reconhecer a necessidade de se avançar na construção de modelos alternativos de intervenção relacionados ao uso de drogas, cujas concepções se contraponham à visão preconceituosa, alarmista e repressora do fenômeno, centrada no discurso anti-droga.

De acordo com esse referencial, os programas voltados para a prevenção ao uso abusivo de drogas devem abordar a dimensão sócio-econômica $e$ política deste fenômeno, assim como as representações e práticas da população relativas aos diversos aspectos do tema. Dentro deste ponto de vista ganha destaque a abordagem da "redução de danos". Contraposta à política repressiva de "guerra as drogas", tal perspectiva tem por base dois pressupostos: o precedente histórico da inexistência de sociedades que tenham prescindido do uso de psicoativos; e que tais usos determinem o mínimo de danos e o máximo de alívio e bem-estar a indivíduos e comunidades. Salienta-se assim, a importância de se avaliar os danos que se quer evitar, procedendo a uma classificação e hierarquização exaustiva dos mesmos. Para tal considera-se ser prioritária a ação educativa preventiva, com especial ênfase no importante papel dos sistemas públicos de educação e de saúde nessas ações (Ministério de Saúde, 1999).

Priorizar a ação educativa não significa operar com a dicotomia preventivo versus curativo (Camargo Jr., 1999). Este pressuposto serve de apoio à análise dos benefícios e alcances da abordagem de "redução de danos", tanto nas ações preventivas quanto terapêuticas, que incluem não apenas os usuários em potencial, os experimentadores e os usuários ocasionais, mas também os dependentes químicos. Tais benefícios podem ser ilustrados por avaliações de programas de prevenção no contexto escolar (Soares, 1997) e por análises das políticas de distribuição de seringas para usuários de drogas injetáveis (Mesquita \& Bastos, 1994).

Convém informar que o desenvolvimento do Jogo da Onda foi norteado pelas considerações expostas acima. Tal abordagem encontra ressonância em uma determinada visão crítica da educação (Borges, 1996; Melo, 1993; L'Abbate, 1994; Oshiro, 1988), que repercute nas discussões sobre a natureza educativa do trabalho de prevenção no campo da saúde e, conseqüentemente, na análise das repercussões de tecnologias educacionais.

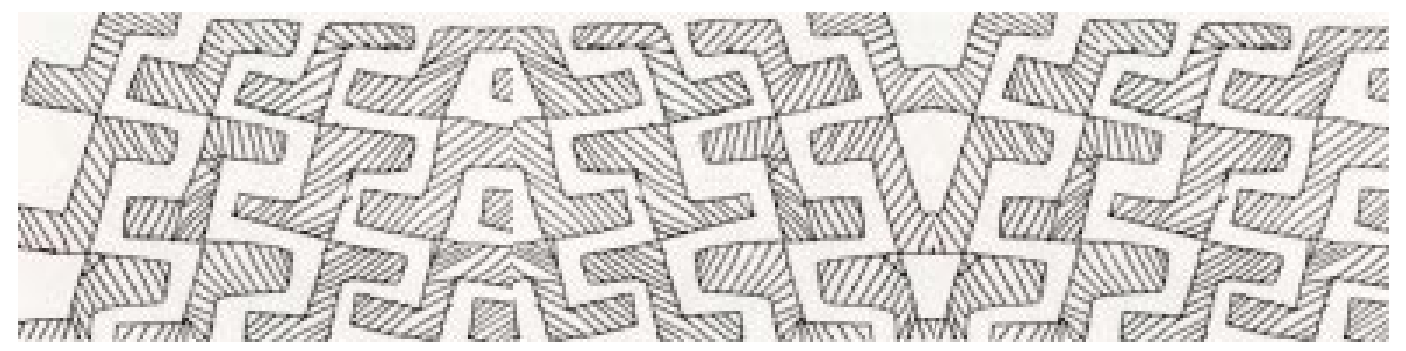




\section{Metodologia}

\section{Caracterização da amostra}

Fizeram parte da investigação 62 estudantes, $54,8 \%$ do sexo feminino $e$ $45,2 \%$ do sexo masculino, matriculados na $8^{\text {a }}$ série e no $1^{\circ}$ ano do curso médio, sendo $90 \%$ da faixa etária entre 12 e 18 anos. Na seleção da amostra levou-se em conta o interesse dos/as alunos/as em participarem do trabalho. Integraram também o estudo 17 profissionais inseridos em programas de prevenção, 15 dos quais da rede pública de ensino. O critério de seleção desse educadores não privilegiou a formação acadêmica ou a disciplina lecionada $e$ sim a sua disponibilidade 8 .

Para a composição da amostra foram selecionados quatro estabelecimentos de ensino. Tendo em vista a influência do contexto sóciocultural na produção das práticas dos sujeitos, procurou-se contemplar unidades localizadas em regiões metropolitanas do Rio de Janeiro com perfil social econômico diversificado. Para tal foram escolhidos estabelecimentos nas seguintes localidades: Caxias e Xerém (municípios contíguos ao município do Rio de Janeiro); Gávea e Copacabana (zona sul do município/ $\mathrm{RJ}$ ). Na zona sul do município do Rio de Janeiro há uma concentração da população de maior poder aquisitivo, embora existam favelas em alguns morros desta área. No município de Caxias e em Xerém prevalece o segmento populacional de baixa renda. Em ambas localizações existem áreas de tráfico de drogas.

\section{Estratégias metodológicas}

No presente estudo adotou-se como estratégias: a realização de grupos focais com alunos/as; a observação direta das partidas com alunos/as e a aplicação de questionários com estudantes e professores após as partidas. Em cada unidade de ensino foram realizadas as seguintes etapas: a) um grupo focal com oito alunos/as que não haviam jogado; b) uma partida com oito alunos/as com a presença de um professor; seguida da aplicação de questionários; c) uma partida com oito alunos/as sem professor, seguida da aplicação de questionário; d) um grupo focal com oito alunos/as que haviam participado de uma dessas partidas; e) aplicação de questionários em professores.

A adoção de procedimentos variados e complementares, como grupo focal, observação direta das partidas do jogo e questionário, se fez necessária à articulação entre a problemática proposta e o quadro teórico de referência da pesquisa, indicado anteriormente. Face à diversidade das técnicas utilizadas e o caráter complementar de seu uso, convém tecer algumas considerações sobre as mesmas.

A utilização de grupos focais representou uma fonte de informação privilegiada acerca dos significados atribuídos

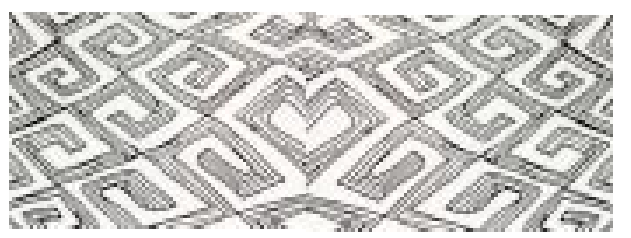
pelos/as jovens aos temas relativos ao consumo de drogas abordados no Jogo da Onda, tais como: conceitos e efeitos das drogas; motivações
${ }^{8}$ Este projeto contou com a colaboração de participantes do "Projeto de Prevenção às DST/AIDS e ao abuso de drogas nas escolas públicas estaduais e municipais do Rio de Janeiro"denominado de "Ser Vivo", coordenado pelas Secretarias Estaduais de Saúde e Educação/RJe Municipal de Educação/ $\mathrm{RJ} e$ apoiado pela Coordenação Nacional de DST/AIDS -

Ministério da Saúde. A coordenação do Projeto pretende distribuir 9.000 unidades do Jogo da Onda para os alunos/as (monitores) que serão treinados pelos professores capacitados. 
${ }^{9}$ As sessões foram coordenadas por uma pesquisadora (com formação em psicoterapia) $e$ observadas por uma segunda pesquisadora (com formação em educação em saúde) e tiveram duração média de uma hora e quinze minutos; os encontros foram gravados com o consentimento dos escolares. para o consumo; visão acerca do usuário de drogas; uso de drogas e relações familiares/afetivas; drogas e AIDS; pressão social/dificuldades na vida cotidiana; drogas e legislação ${ }^{9}$. Ademais, permitiu a identificação da visão dos/as alunos/as sobre o jogo, bem como de demais trabalhos no campo da prevenção do HIV/AIDS e do abuso de drogas.

$\mathrm{O}$ uso desta técnica nas pesquisas científicas permite lançar luzes sobre as opiniões, crenças e práticas de um grupo social (Dawson et al., 1992, p.3-4), bem como orientar a formulação das hipóteses e do desenho de um projeto. Soares (1997) destaca a utilização de grupos focais na abordagem qualitativa de pesquisa em Educação em Saúde, planejamento de programas, avaliação processual e de resultados. Segundo a autora, sua importância reside em seu potencial de "gerar hipóteses, descobrir percepções e atitudes de pequenos grupos, obter informações e estimular novas idéias" (1997, p.117).

Pode-se observar que os grupos focais, além de cumprirem a finalidade de instrumento de pesquisa, constituem um meio de reflexão para os participantes. Os/as escolares, em geral, manifestaram interesse e disponibilidade para relatar suas experiências, agradeceram a oportunidade oferecida e reiteraram o desejo de participar de situações semelhantes.

Quanto à observação das partidas, optou-se pela observação direta do uso do Jogo da Onda em grupos de alunos/as, orientada por um roteiro, com $e$ sem a presença de um profissional de ensino. Tal opção favorece a identificação de diversos aspectos referentes ao contexto de aplicação do jogo, quais sejam: 1) influência da presença de um educador ou liderança juvenil na partida; 2) compreensão, respeito e adaptações às regras; 3 ) interesse pela dinâmica de abordagem dos temas e entendimento do conteúdo do jogo; 4) entrosamento e participação dos estudantes e demais fatores relativos à motivação pelo jogo. Para Lopes (1994), a observação direta dos fatos no processo de pesquisa em Comunicação Social, a partir de situações interativas, permite o registro dos diversos fatores, esperados ou não, que surgem no decorrer da investigação.

A aplicação dos questionários aos alunos/as proporcionou informações complementares sobre o recurso educativo quanto à capacidade do jogo de gerar interação e debate, fornecer informação, fomentar a expressão das opiniões dos participantes e esclarecer dúvidas. Foram ainda registradas as opiniões sobre outros recursos envolvendo o tema da prevenção do uso de drogas, bem como críticas e sugestões em relação ao jogo. O questionário dirigido para os educadores, além desses temas, continha informações sobre o número de vezes que o jogo foi utilizado, o contexto de aplicação, a faixa etária e o nível de escolaridade do grupo. Destaca-se que os questionários foram preenchidos pelos próprios informantes.

Cabe ainda informar alguns procedimentos adotados na análise dos dados. No que se refere às informações provenientes dos grupos focais e dos registros das observações das partidas, estas foram organizadas, num primeiro momento, em torno dos temas estruturantes dos respectivos roteiros. Em seguida, identificarram-se as recorrências e singularidades dos assuntos. Quanto às informações oriundas dos questionários aplicados em alunos e educadores, as respostas computadas foram distribuídas em 


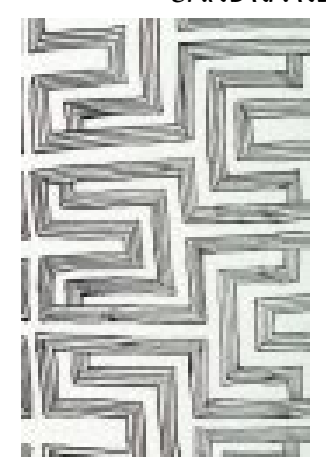

percentuais. Ressalta-se, no tratamento dos dados, que as diferenças de gênero $e$ idade não foram destacadas e sim a origem escolar, cuja variável encontra-se relacionada à variação do perfil socioeconômico das unidades de ensino do estudo. Considera-se que o processo de análise é resultante da articulação dos dados categorizados com a produção acadêmica do campo, conforme indicam os resultados apresentados a seguir.

\section{Análise dos resultados}

\section{Concepção das drogas}

Na perspectiva dos estudantes droga é tudo aquilo que vicia, algo "ilusório", uma coisa "ruim". A ênfase na dimensão negativa, presente no imaginário social, não contempla o debate sobre as implicações do consumo devido $e$ indevido das substâncias psicoativas, a diferenciação de drogas lícitas $e$ ilícitas, bem como a dimensão histórica, econômica, política e sócio-cultural do uso das mesmas. Quer dizer, não leva em conta a contextualização da utilização $e$ a diversidade das substâncias psicoativas na sociedade moderna. Vale destacar que esta concepção generalizante ganha contornos mais específicos a partir de algumas distinções sobre os malefícios de cada substância. Por exemplo, para muitos o cigarro é uma droga apenas porque vicia. Quanto ao álcool, prevalece a idéia de que este só se torna uma droga quando consumido de forma descontrolada. Parte dos/as alunos/as não considera o álcool uma droga. Convém informar que um terço dos 914 jovens participantes do estudo de Minayo et al. (1999) compartilham este ponto de vista.

Diante da pergunta: "Quais as drogas que vocês conhecem?", os/as escolares citaram um amplo leque: LSD, haxixe, heroína, chá de cogumelo, crack, ecstase, calmante, esmalte, acetona, drogas injetáveis, cola e benzina. Todavia, pouco se falou sobre a experimentação, os efeitos e implicações do uso das mesmas. O grupo, em geral, demonstra conhecer apenas os efeitos do álcool, da maconha e da cocaína, consideradas por eles como "drogas básicas". Embora predomine a noção de que a maconha não causa grandes males, as drogas ilegais são consideradas mais prejudiciais porque "matam mais rápido". Tal fato indica que os/as jovens atribuem um estatuto diferenciado às drogas ilegais, procedendo a uma classificação hierárquica ${ }^{10}$ entre as drogas lícitas e ilícitas.

A noção de hierarquia também está presente em outras situações associadas a risco. No campo das práticas sexuais, Monteiro (1999) identificou entre jovens de uma favela carioca que a percepção do preservativo como algo desconfortável, somada à resistência ao uso por parte da/o parceira/o, levam a avaliações sobre uma hierarquia de risco conforme o contexto. De acordo com os meninos, diante de algumas situações (falta da camisinha, problema na negociação) eles cedem e não utilizam ("tento convencer, se eu não conseguir vai sem" - Vitor, 16 anos); mas, em certos casos, eles não abrem mão do uso. João, de 19 anos, diz que
10 O estudo de Connors (1992) revela que a percepção de uma hierarquia de risco associado ao consumo de drogas também está presente entre os usuários de drogas injetáveis. 
no baile funk "a gente não sabe como é as coisas, aí usa (...) se [a menina] não quiser não faz, ela pode estar contaminada”.

\section{Acesso $e$ iniciação}

$\mathrm{Na}$ ótica dos/as estudantes o acesso às drogas é facilitado pelo contexto social e a 'pressão de grupo' é uma realidade. Constata-se que o grupo entra em contato direto com as drogas na rua, no shopping, clubes e bailes. Esses fatores, no entanto, não são considerados os únicos determinantes para a iniciação ao consumo das drogas. A visão dos/as jovens sobre as motivações para o uso revelam uma maior ênfase na responsabilidade individual - "usa quem quer" - ou nas dificuldades pessoais.

A percepção sobre a iniciação ao uso das drogas associada ao cigarro, foi aventada: "é sempre assim, todo mundo começa usando o cigarro depois vai passando para uma mais forte" e "dependendo da pessoa não consegue mais parar". Mais uma vez, nota-se a presença de uma noção de hierarquia relacionada aos riscos decorrentes do consumo de drogas. Além da "curiosidade", os/as jovens alegam que outros fatores contribuem para a iniciação ao uso, tais como: "imitação dos colegas e adultos", a "quebra de tensão", o fato de "sentirem-se como adultos" e o "prazer de fumar". Stewien (1977) já havia identificado a influência de tais fatores. Segundo Goldfard (1999), metade dos jovens que experimentam o cigarro se tornam fumantes quando adultos.

Nas discussões sobre as experiências de consumo de álcool, parte do grupo afirmou que faz um uso controlado. Segundo os/as estudantes, ficar de porre ou usar qualquer droga de maneira abusiva é muito ruim, mas "beber socialmente" é prazeroso. Nota-se assim que os/as jovens entrevistados/as se identificam como usuários "sociais", que consomem principalmente cigarro, álcool e maconha de forma moderada e não correm o risco de fazer uso abusivo. Neste sentido, eles/as se diferenciam do usuário dependente, considerado uma 'pessoa fraca' e 'sem auto-estima'.

Em resumo, por não reconhecerem os potenciais malefícios do consumo, mesmo descontínuo, essa população não percebe os riscos a que poderia estar exposta. Soma-se a este fator a curiosidade de experimentar principalmente drogas lícitas como o álcool e o cigarro, a pressão social e o desconhecimento dos efeitos comportamentais $e$ as conseqüências orgânicas do uso de substâncias psicoativas. Desse modo, pondera-se que a não percepção do risco, combinada à curiosidade, à desinformação $e$ ao acesso contribuem para a iniciação do jovem no consumo de substâncias psicoativas.

11 O papel crucial da família na construção da identidade social $e$ na elaboração do projeto de vida das pessoas, de diferentes segmentos sociais tem sido apontado na literatura sociológica (Durham, 1983; Velho 1987; Sarti, 1996)

\section{Os jovens $e$ as relações com a família}

Procurou-se identificar em que medida os/as jovens compartilham com os pais as experiências, dúvidas e questões relacionadas ao consumo de drogas, tendo em vista que a construção da identidade do sujeito efetiva-se nas relações com os outros e que a família constitui o primeiro núcleo socializador da criança ${ }^{11}$. Durante as observações das partidas, pode-se 
constatar que as cartas do jogo referentes ao assunto família geraram grandes discussões sobre o valor, as dificuldades e os problemas das relações familiares, sugerindo uma mobilização do grupo em torno desta temática. No entanto, a maioria dos/as entrevistados/as relata ter dificuldade de dialogar de forma "aberta" com os pais sobre sexo e drogas. Para alguns jogar o Jogo da Onda com a família seria uma oportunidade de conversar acerca do tema; outros, contudo, afirmaram que não se sentiriam à vontade para falar a "verdade", com medo de serem repreendidos.

É importante assinalar que do ponto de vista do/a jovem abordado pelo presente estudo a atitude de controle dos pais ocasiona o afastamento entre pais e filhos. Tal percepção indica a relativa eficácia da postura repressiva da família na prevenção do uso indevido drogas, principalmente o álcool. No que diz respeito ao uso de drogas e às relações familiares, alguns estudos, como o de Abramovay et al. (1999) e Minayo et al. (1999), indicam que apesar dos problemas e conflitos existentes, a família continua sendo uma das principais referências para os jovens, representando um locus de apoio $e$ confiança.

A escola foi considerada "o lugar ideal" para se abordar assuntos relacionados à prevenção ao HIV e ao uso abusivo de drogas. Todavia, a experiência dos jovens revela a escassa disponibilidade dos professores em tratar tal tema. Segundo os/as alunos/as, na maioria das vezes, os educadores falam pouco sobre essas questões: "eles têm um bloqueio". Assim, em detrimento da importância atribuída à instituição familiar e escolar, no que tange à vivência do jovem, não existe nesses espaços de sociabilidade um diálogo franco acerca do assunto drogas, conforme demandam os/as escolares.

\section{Legislação e relações dos jovens com o poder público}

Observa-se que a maioria dos/as jovens sabe distinguir drogas lícitas e ilícitas. Predomina a idéia de que algumas substâncias não são legalizadas porque existe interesse político e comercial: "nosso país é governado por pessoas governadas por indústrias". Alguns acreditam que se as drogas ilícitas fossem comercializadas haveria um aumento do uso, para outros tal ação não interferiria no consumo. Há ainda os que acreditam que a proibição "não leva a nada" podendo, inclusive, estimular o consumo.

Algumas das sugestões do grupo sobre alternativas de reformulação da legislação vigente aproximam-se da atual proposta de discriminação, na qual se retira o ato de consumir drogas da esfera penal, mantendo nesta esfera as atividades de tráfico. Suas falas são ilustrativas: "para usuários, clínica de recuperação"; "caçaria os traficantes e faria trabalhos de prevenção em escolas e hospitais"; "se eu tivesse autoridade eu colocava todos os viciados

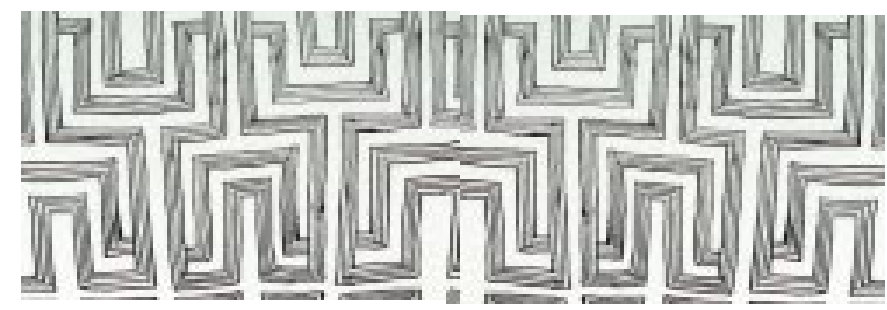
para tratamento"; "cobraria impostos altos e reverteria para o tratamento das pessoas". Há ainda posições a favor da proibição de algumas drogas lícitas, ilustradas pelas 
seguintes falas: "álcool e cigarro também têm que entrar no mesmo rigor da lei", "ia botar fogo geral, contra a comercialização de qualquer droga".

Nos debates relativos aos procedimentos legais diante de um flagrante relacionado ao uso de drogas ilícitas, a falta de confiança na polícia foi tema recorrente. Há uma descrença nas instâncias governamentais responsáveis pela segurança da população, bem como no cumprimento das leis pelo povo: "ninguém segue a lei no Brasil". Alguns jovens criticaram a ausência do poder público na promoção da segurança da população. Nota-se assim, uma demanda dos jovens por ações de controle das drogas no âmbito público, particularmente em determinados contextos, conforme revela um escolar: "as pessoas deveriam ser revistadas [nos bailes]".

A discussão das relações dos jovens com o poder legal e o poder ilegal perpassou todos os grupos de discussão. Na visão dos/as estudantes a polícia tem atitudes agressivas e desrespeitosas. Os depoimentos são ilustrativos: "tenho mais medo deles do que dos traficantes, não respeitam ninguém", "além de traficar, usam e vendem a droga apreendida". Alguns procuram justificar tais atitudes, alegando que os policiais ganham pouco e por isso são corruptos. Por outro lado, o traficante é visto como um "comerciante" que ganha dinheiro com as drogas, mas não faz uso das mesmas. Há um reconhecimento de que o bandido faz mal, contudo "dá presente" e parece ser mais confiável do que o policial. Portanto, as representações em torno da figura do bandido pendem para uma visão mais positiva quando comparada à polícia e assemelham-se às encontradas na literatura (Zaluar, 1985, 1994; Fonseca, 1993; Monteiro, 1999; Assis, 1999). No contexto do estudo de Zaluar (1994), ressalta-se que as representações do bandido, comumente contrapostas à figura do policial, apresentam-se como resultante de um mecanismo de exclusão social que afeta a juventude e encontra-se intimamente relacionado, dentre outros fatores, a uma crise de ética do trabalho na nossa sociedade.

Em que pese uma percepção mais ou menos homogênea, pode-se observar algumas diferenças de visão entre os estudantes associadas às particularidades econômicas e sociais das localidades do estudo. Algumas observações endossam este ponto de vista. Em uma escola do subúrbio notou-se uma disposição para ações preventivas nesse campo, com predomínio de atitudes de solidariedade e de valores apoiados em relações de reciprocidade no âmbito familiar e local. Esta escola caracteriza-se por estar situada em uma área mais distanciada do centro urbano, embora pertença à região metropolitana do Rio. Já em uma das escolas da Zona Sul, próxima à área de tráfico, prevaleceu um descrédito por parte do jovem em relação às perspectivas de mudança. Na visão deste grupo não é possível reverter esta situação, ela se encontra em toda parte; tal cenário reflete a ausência de alternativas para se lidar com questões relacionados ao uso e ao tráfico de drogas. Semelhante a esta postura foi a percepção dos jovens de outra escola situada na zona norte próxima ao comércio ilegal de drogas.

Observa-se que os jovens pertencentes às regiões mais próximas do tráfico e de intervenções policiais repressivas têm maior receio em abordar as experiências de violência; em contraste com o relato mais espontâneo daqueles que se apresentam, aparentemente, mais distanciados do comércio 
ilegal de drogas. Aparentemente porque o uso de drogas lícitas e ilícitas é realidade em todas as localidades que compõem a amostra e grande parte dos/as alunos/as convive com familiares que fazem uso abusivo de álcool.

\section{Opiniões sobre o Jogo}

Os dados sobre a opinião dos jovens e das educadoras acerca da aceitação $e$ motivação do uso do Jogo da Onda indicam que este é um recurso capaz de informar, promover a reflexão e estimular o debate acerca de várias situações cotidianas relacionadas ao uso de drogas. Grande parte $(79,0 \%)$ dos/as alunos/as atribuiu ao jogo o conceito "muito bom", considerando-o informativo e interativo; $80,0 \%$ afirmaram que por meio desse material é possível conhecer melhor a opinião dos colegas; cerca de $70 \%$ responderam que podem expressar plenamente suas opiniões; $98,4 \%$ concordam que o jogo ajuda a compreender temas referentes ao uso de drogas, particularmente os conceitos e efeitos das drogas e sua relação com o contexto familiar; 98,4\% afirmaram que gostariam de jogar novamente.

$\mathrm{Na}$ opinião das educadoras o jogo atinge seus objetivos quanto a gerar debates, fornecer informação e esclarecer dúvidas de forma satisfatória. Para $64,7 \%$ o Jogo da Onda é um instrumento pelo qual os/as alunos/as conseguem expressar suas opiniões; $82,3 \%$ consideram que este material estimula a interação e comunicação dos participantes. Para as profissionais de ensino o caráter dinâmico dos jogos marca a diferença entre estes e os demais materiais educativos, além de motivar as diversas faixas etárias. Embora $70,6 \%$ tenham revelado não ter dificuldade na aplicação do material, alguns problemas foram apontados, como leitura e compreensão do conteúdo das cartas e das regras. Todavia, essas dificuldades foram superadas com a ajuda de um facilitador (educador) ou de um dos jogadores.

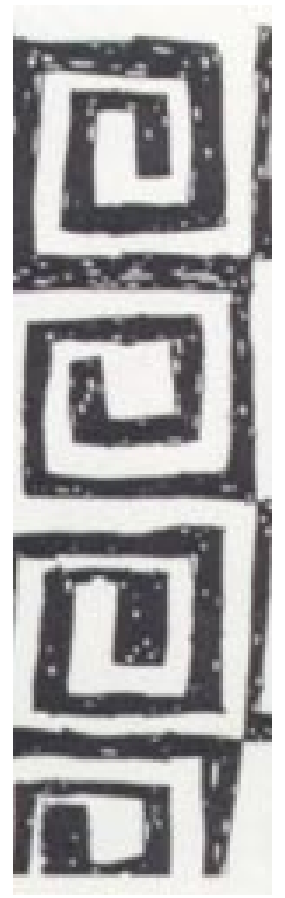

\section{Considerações finais}

A proposta de investigar o conhecimento da visão de estudantes sobre os temas abordados no Jogo da Onda apóia-se na idéia da relevância da percepção do usuário na avaliação do alcance das mensagens veiculadas em recursos de Educação em Saúde. Tal perspectiva busca trazer para o contexto educacional as experiências e representações do educando acerca da temática em foco, tendo em vista as diferenças socioeconômicas e culturais entre os segmentos populacionais que integram as sociedades modernas. Desta forma, procura-se diferenciar das proposições educativas que enfatizam a transmissão de informações, definidas a priori e distanciadas da realidade dos sujeitos aos quais as mensagens são dirigidas.

Ao privilegiar a visão dos/as estudantes foi possível identificar os contrastes entre o discurso preventivo repressivo $e$ as motivações para a experimentação de drogas (lícitas e ilícitas). Observa-se que a iniciação ao uso está relacionada a um conjunto 
de fatores, como pressão social de grupo, fácil acesso às drogas e ao não reconhecimento de que o consumo pessoal, mesmo descontínuo, pode levar à dependência química. Notou-se, ainda, uma ausência de confiança da maioria dos jovens na polícia, identificada como a instituição do aparato do Estado responsável pela segurança da população. Foi observado que as visões dos/as escolares encontram pontos de convergência com a produção acadêmica neste campo. No entanto, observa-se que tais concepções, em geral, não são consideradas nas campanhas sobre o abuso de drogas, centradas numa abordagem alarmista $e$ preconceituosa do fenômeno.

Dito de outro modo, determinadas dissonâncias entre visão do grupo pesquisado e discurso preventivo repressivo e/ou técnico informativo sugere a necessidade de os programas educativos valorizarem as formas de apreensão e as repercussões das informações transmitidas. Compreende-se que este enfoque pode revelar o alcance das metas esperadas e sugerir reformulações nas ações $e$ investigações no campo da Educação em Saúde.

Além da caracterização da visão dos usuários sobre as referidas temáticas, buscou-se verificar o estímulo e aceitação dos escolares e de alguns educadores sobre o uso do Jogo da Onda em contexto educacional. Este ponto de vista refere-se à valorização da motivação $e$ da interatividade no processo de ensino e aprendizagem. O grupo pesquisado afirmou ser o jogo um recurso motivante, capaz de gerar aprendizagem, promover o diálogo e o debate sobre situações relacionadas ao uso de drogas. Com base nas observações colhidas assinala-se que este jogo pode facilitar a abordagem do tema drogas na escola e na família, consideradas instituições sociais importantes para a formação dos indivíduos, que em muitos casos têm dificuldade de tratar tal assunto.

Convém acrescentar que os/as escolares demonstram interesse em participar de programas de prevenção. A maioria já teve acesso a informações sobre drogas por meio de materiais pedagógicos diferenciados (folhetos, vídeos) e atividades diversas (palestras, teatro, feira de ciências), sendo as propostas interativas que favorecem o diálogo - como os jogos as mais valorizadas. Por outro lado, as ações predominantemente informativas foram criticadas.

É importante citar que um dos desdobramentos do presente estudo foi a ampliação do Jogo da Onda por meio da introdução de novas cartas, já em andamento, sobre os conteúdos abordados e demais temas da adolescência, principalmente saúde sexual e reprodutiva e relações de gênero. Tal proposta visa incorporar as sugestões dos jovens participantes da investigação. Pretende-se ainda acrescentar novas sugestões ao encarte que acompanha o jogo (composto de bibliografia e dicas das implicações dos contextos de uso do material). Outro desdobramento da investigação referese à divulgação de seus resultados para os profissionais de ensino da rede pública, em seminários. As discussões revelaram a importância da devolução dos dados da pesquisa no incremento da prática pedagógica em saúde.

Em suma, por meio desta investigação, buscou-se demonstrar em que medida a análise do ponto de vista dos usuários possibilita a avaliação da 
adequação e aperfeiçoamento de um material educativo sobre o uso indevido de drogas e, conseqüentemente, colabora para a formulação de propostas de Educação em Saúde mais efetivas e estimulantes.

\section{Referências bibliográficas}

ABRAMOVAY, M., WAISELFISZ, J., ANDRADE, C., RUA, M. G. Gangues, galeras, chegados e rappers: juventude, violência e cidadania nas cidades da periferia de Brasília. Rio de Janeiro: Garamond, 1999.

ASSIS, S. G. Traçando caminhos em uma sociedade violenta: a vida de jovens infratores e de seus irmãos não infratores. Rio de Janeiro: Editora Fiocruz, 1999.

BARROS, C. R., MATHIAS, C. R., CASTRO, D. M. et al. Catálogo Projeto Prisma - região Sudeste. Rio de Janeiro: UERJ, 1999.

BASTOS, I. F. Ruína \& reconstrução: AIDS e drogas injetáveis na cena contemporânea. Rio de Janeiro: Relume Dumará/ABIA/IMS/UERJ, 1995.

BORGES, S. N. Metamorfoses do corpo: uma pedagogia Freudiana. Rio de Janeiro: Editora Fiocruz, 1996.

BUCHER, R. Drogas e drogadição no Brasil. Porto Alegre: Editora Artes Médicas, 1992.

CAMARGO JR., K. R. Políticas públicas e prevenção em HIV/AIDS. In: PARKER, R., GALVÃO, J., BRESSON, M. (Orgs.) Saúde, desenvolvimento e política: respostas frente à AIDS no Brasil. São Paulo: Ed. 34, 1999. p.227-62.

CASTIEL, L. D. O buraco e o avestruz: a singularidade do adoecer humano. São Paulo: Papirus, 1994.

CONNORS, M. Risk perception, risk taking and risk management among intravenous drug users: Implications for AIDS prevention. Soc. Sci. Med., v.34, p.591-601, 1992.

CORTES, B. A. O jogo da onda: um convite ao diálogo. Hist. Ciênc. Saúde, v.5, n.3, p.762-5, 1999.

DAWSON, S., MANDERSON \& TALLO, V. The focus group manual: methods for social research in tropical diaseases. sl: UNDCP/World Bank/WHO - Special Programme for Research and Training in Tropical Diseases (TDR). 1992. (mimeogr.)

DURHAM, E. Família e reprodução humana. In: FRANCHETTO et al. (Orgs.) Perspectivas antroloplógicas da mulher. Rio de Janeiro: Zahar, 1983. p.13-44.

ESCOHOTADO, A. O livro das drogas: usos e abusos, preconceitos e desafios. São Paulo: Dynamis Editorial, 1997.

FONSECA, C. Bandidos e mocinhos: antropologia da violência no cotidiano. Humanas: revista da IFCH - UFRGS, v.1, n.2, p.67-89, 1993.

GOLDFARB, L. Tabagismo: estudos em adolescentes e jovens. In: SCHOR, N., MOTA, M.S., CASTELO BRANCO, V. (Orgs) Cadernos juventude, saúde e desenvolvimento. Brasília:

Ministério da Saúde, Secretaria de Políticas de Saúde, 1999. p.162-72.

INEM, C., ACSELRAD, G. (Orgs) Drogas: uma visão contemporânea. Rio de Janeiro: Imago, 1993.

L'ABBATE, S. Educação em Saúde: uma nova abordagem. Cad. Saúde Pública, v.20, n.4, p.481-90, 1994.

LOPES, M. I. V. Pesquisa em Comunicação: formulação de um modelo metodológico. São Paulo: Loyola, 1994.

MELO, J. A. C. (Org.) Educação: razão e paixão. Rio de Janeiro: Panorama, ENSP, 1993.

MELO, J. M. Comunicação: teoria e política. São Paulo: Summus, 1995.

MESQUITA, F., BASTOS, F. (Orgs.) Drogas e AIDS: estratégias de redução de danos. São Paulo: Hucitec, 1994.

MINAYO, M. C. S., ASSIS, S. G., SOUZA, E. R. et al. Fala galera: juventude, violência e cidadania. Rio 
de Janeiro: Garamond, 1999.

BRASIL. MINISTÉRIO DA SAÚDE. Sexualidade, prevenção das DST/AIDS e uso indevido de drogas: diretrizes para o trabalho com crianças e adolescentes. Brasília, 1999.

MONTEIRO, S. Gênero, sexualidade e juventude numa favela carioca. In: HEILBORN, M. L. (Org.) Sexualidade: o olhar das Ciências Sociais. Rio de Janeiro: Zahar, 1999. p.117-45.

MONTEIRO, S., REBELLO, S., SCHALL, V. Jogando e aprendendo a viver: uma abordagem da AIDS e das drogas através de recursos educativos. In: MESQUITA, F., BASTOS, F. (Orgs.) Drogas e AIDS: estratégias de redução de danos. São Paulo: Hucitec, 1994. p.133-46.

NETO, A. F. A deflagração do sentido. Estratégias de produção e de captura da recepção. In: SOUZA, M. W. (Org.) Sujeito, o lado oculto do receptor. São Paulo: Brasiliense, Escola de Comunicação eArtes/USP, 1995. p.189-222.

OSHIRO, J. Educação para Saúde nas instituições de Saúde Pública. São Paulo, 1988. Dissertação (Mestrado). Pontifícia Universidade Católica de São Paulo.

SÁ, D. T., SIQUEIRA, V. H. F., MARTELETO, M. A. Demanda e clientela multiprofissional para um mestrado em Tecnologia Educacional nas Ciências da Saúde. Cad. Saúde Pública, v.15, n.2, p. 44-53, 1999.

SARTI, C. A família como espelho: um estudo sobre a moral dos pobres. São Paulo: Autores associados, 1996.

SCHALL, V., MONTEIRO, S., REBELLO, S., TORRES, M. Evaluation of the Zig-Zaids game: an entertaining educacional tool for HIV/AIDS prevention. Cad. Saúde Pública, v.15, n.2; p.107-19, 1999.

SOARES, C. Adolescentes, drogas e AIDS: avaliando a prevenção e levantando necessidades. São Paulo, 1997. Tese (Doutorado) Universidade de São Paulo.

STEWIEN, G. T. M. O adolescente e o fumo. São Paulo, 1977. Dissertação (Mestrado) Faculdade de Saúde Pública, Universidade de São Paulo.

VARGAS, E. P., SIQUEIRA, V. Sexualidade e corpo: o olhar do sujeito através das imagens em vídeo. Cad. Saúde Pública, v.15, n.2, p.69-83, 1999.

VARGAS, E. V. Os corpos intensivos: sobre o estatuto social do consumo de drogas legais e ilegais. In: DUARTE, L. F., LEAL, O. F. (Orgs.) Doença, sofrimento, perturbação: perspectivas etnográficas. Rio de Janeiro: Editora Fiocruz, 1998. p.133-46.

VELHO, G. Pensando a família no Brasil: da colônia à modernidade. Rio de Janeiro: Espaço e Tempo/UFRJ, 1987.

ZALUAR, A. A máquina e a revolta: as organizações populares e o significado da pobreza. São Paulo: Brasiliense, 1985.

ZALUAR, A. Condomínio do diabo. Rio de Janeiro: Revan \& Universidade Federal do Rio de Janeiro, 1994.

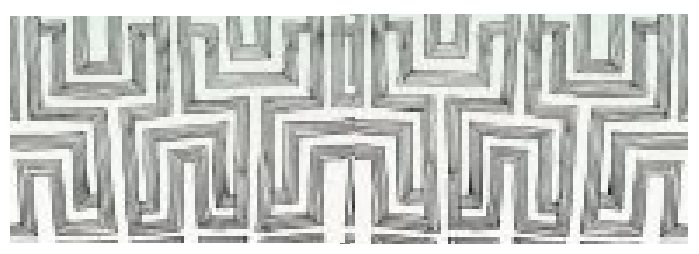

fevereiro, 2001 


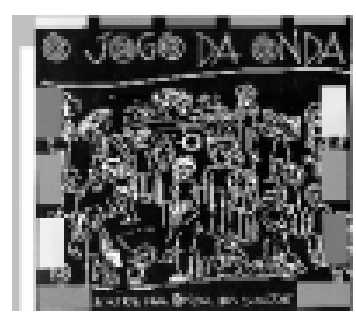

Jogo da Onda

De forma divertida e educativa, o Jogo da Onda incentiva e incrementa o diálogo entre jovens, educadores, pais, filhos, amigos e profissionais sobre o uso indevido de drogas. Para 4 a 8 participantes (organizados em duplas). Recomendado para maiores de 12 anos, é adequado para contextos do ensino formal e informal, podendo ser adaptado para diferentes realidades, inclusive programas dirigidos para dependentes químicos, conforme indica o encarte que acompanha o material.

Contém: um tabuleiro; quatro baralhos coloridos que abordam temas relativos à: família, relacionamento, sexualidade, dependência, drogas e seus efeitos, tratamento, legislação, AIDS, entre outros; um dado simples; quatro pinos e um encarte com dicas de atividades e sugestões bibliográficas.

\section{Como adquirir o JOGO da ONDA?}

Edições Consultor

Ediçoseral Gurjão, 479

Rio $20931-041$

Caju, Rio de Janeiro

Tel: (21) 5893030

A FIOCRUZ pode doar um exemplar para A instituições públicas e da socicação para:

Encaminhe sua solici

LEAS - Biologia/lação Oswaldo Cruz

A/C Simone Monteiro

Av. Brasil, 4365

Manguinhos, Rio de Janeiro/ RJ.

CEP: 21045900

Telefax: (21) 5606474

REBELLO, S.; MONTEIRO, S.; VARGAS, E. Visión de los escolares sobre drogas mediante el uso de um juego educativo. Interface _ Comunic, Saúde, Educ, v.5, n.8, p.75-88, 2001.

Este estudio enfatiza la relevancia de la mediación cultural en el uso de tecnologías educacionales. Para eso, se describe la percepción de 62 escolares de la red pública de Rio de Janeiro sobre temas abordados en el jogo da Onda, un juego sobre el uso de drogas, y el interés del grupo por el material. A partir de grupos focales, observación de las partidas y cuestionarios, se observó que la iniciación al uso de drogas está relacionada a: presión social de grupo, fácil acceso a las drogas y al no reconocimiento de que el consumo personal, aún cuando sea discontinuo, puede llevar a la dependencia química. Disonancias entre la visión de los escolares y el discurso preventivo represivo y/o técnico informativo sugieren que las acciones educativas deben privilegiar formas de aprensión de las informaciones transmitidas, enfocando la interactividad, la interlocución, la información y la reflexión.

PALABRAS CLAVE: transtornos relacionados con substancias; tecnología educacional; percepción social. servicios de la salud preventiva; estudiantes 